\title{
A IMPORTÂNCIA DO USO DE FERRAMENTAS DE PLANEJAMENTO E CONTROLE EM OBRAS DE RESTAURAÇÃO: UM ESTUDO DE CASO
}

\author{
PEREIRA E ALVARENGA, MAJDA \\ Graduanda em Engenharia Civil \\ Universidade Federal de Ouro Preto \\ Minas Gerais; Brasil \\ majda.alvarenga@aluno.ufop.edu.br
}

\author{
CARVALHO MAZZINNI, RAYANE \\ Engenheira Civil \\ Universidade Federal de Ouro Preto \\ Minas Gerais; Brasil \\ rayane_mazzini15@hotmail.com
}

\section{CASTRO MENDES, JÚLIA}

Engenheira Civil, D. Sc.

Universidade Federal de Ouro Preto

Minas Gerais; Brasil

julia.mendes@ufop.edu.br

\author{
PEREIRA SANTANA, VANESSA \\ Mestranda em Engenharia Civil \\ Universidade Federal de Ouro Preto \\ Minas Gerais; Brasil \\ vanessa.pesantana@gmail.com
}

\author{
Engenheiro Civil, D. Sc. \\ Universidade Federal de Ouro Preto \\ Minas Gerais; Brasil \\ guilhermebrigolini@ufop.edu.br
}

BRIGOLINI SILVA, GUILHERME JORGE

\section{RESUMO}

O planejamento e o controle de obras bem realizados são fatores fundamentais para a viabilidade financeira de um empreendimento, especialmente no tocante a restauro de edificações. Assim, este trabalho busca avaliar o processo de planejamento e controle de obras de restauração através de um estudo de caso da obra de restauração da Igreja Santo Antônio de Glaura, em Ouro Preto - MG, iniciada no ano de 2019. Para esta análise, foram realizadas pesquisas bibliográficas, entrevistas com profissionais, visitas de campo e avaliação documental de cronogramas físicos e financeiros, histogramas, escopo do processo, relatórios de gestão de compra e presença de efetivo na obra. Apesar das adiversidades relatadas, a boa aplicação das ferramentas de controle e planejamento conduziu ao cumprimento do cronograma e do orçamento planejados e melhor qualidade da execução, mostrando a importância da utilização de técnicas e ferramentas para obras de restauro.

Palavras-chave: Planejamento de obras, Controle de obras, Restauração, Patologias, Igreja Histórica.

\section{ABSTRACT}

The planning and control of constructions works are fundamental factors for the financial viability a project, especially regarding restoration of historical buildings. Thus, this work aims to evaluate the process of planning and control of restoration works through a case study of the restoration of Santo Antônio de Glaura Church, in Ouro Preto - MG, which started in 2019. For this analysis, we carried out bibliographic research, interviews with professionals, field visits and documentary evaluation of physical and financial schedules, histograms, scope of the process, purchase management reports and staff planning. Despite the problems faced, the good application of control and planning tools led to compliance with the planned schedule and budget and better quality of execution, showing the importance of using techniques and tools for these restoration works.

Keywords: Construction planning, Constructions control, Restoration, Pathologies, Historic Church.

\section{INTRODUÇÃO}

As obras de restauro são indicadas aos bens tombados e aos bens patrimoniais de grande significância para a comunidade (IPHAN, 2005). A restauração de edificações históricas visa não apenas preservar a capacidade documental, mas também a integrigade da obra de arte que esteja presente na edificação. Um dos pontos mais destacáveis ao se avaliar uma obra de restauro é a grande dificuldade em se estabelecer um padrão construtivo, uma vez 
que cada caso deverá ser avaliado isoladamente e não há a possibilidade de se enquadrar o escopo de serviços em tabelas de custos padrão. Dessa forma, cada empreendimento apresenta um conjunto de elementos característicos, e somente a partir da avaliação das patologias que ameaçam a integridade da obra, é possível elaborar uma proposta adequada de intervenção (CAMPANA, 2003).

Para a realização de intervenções em qualquer edificação de valor cultural é necessário que se tenha conhecimento da história do momumento, materiais e sistemas contrutivos, sua importância para a sociedade, estado de conservação, patologias e origens dos danos. Além disso, para a concretização eficiente de obras de restauração é necessário reconhecer a exigência de coordenação das atividades envolvidas no empreendimento, compreendendo planejamento, controle, organização, direção para análise e validação das soluções adotadas para os contratempos encontrados em campo (BOMFIM, 2017; CAMPANA, 2003).

O planejamento de obras é descrito por muitos autores como um processo de tomada de decisão, com base em estudos, índices e cronogramas, que objetiva a idealização do futuro e a elaboração de formas para alcançá-lo. Este processo se faz eficiente apenas quando acompanhado de um rigoroso controle, e por isso, o controle e o planejamento se apresentam como dois elementos interdependentes (LAFETÁ, 2013; ALIANI, 2015). Através do planejamento é possível a conciliação entre os processos contrutivos necesários e os custos operacionais para execução das ações de conservação ou restauro.

Erros na etapa de planejamento de um projeto ocasionam diversas consequencias que podem inviabilizar o empreendimento, uma vez que estes erros se multiplicam nas próximas fases, demandando mais custos e ações corretivas (BERNARDES, 2001). A falta ou insuficiência de planejamento podem resultar em fatores indesejáveis no processo construtivo tais como o desperdício, má gestão de tempo e recursos e movimentação desnecessária de materiais e pessoas, ocasionando a baixa produtividade e baixa qualidade final dos produtos (LIMA, 2016).

Segundo Oliveira (2015), o planejamento operacional é o meio de formalizar as técnicas e ferramentas que serão utilizadas, iniciadas normalmente pela hierarquia mais baixa, para que a equipe consiga atingir os objetivos das hierarquias superiores de forma mais otimizada possível. Dentro do planejamento operacional há também uma hierarquização das decisões, caracterizadas pelo prazo estabelecido para execução (curto, médio e longo prazo) (MATTOS, 2010). Conforme alega Bernardes (2001), todas estas etapas são fundamentais para o sucesso do planejamento completo, sendo utilizadas com objetivos diferentes em termos de apresentação de execução das atividades para o cliente.

A divisão hierarquizada pelo prazo pode ser abordada principalmente aspectos financeiros, escolhas de marcos contratuais e etapas da obra (GOLDMAN, 2004). Muitas vezes, o planejamento a longo prazo é executado através de técnicas como o cronograma físico-financeiro e gráfico de Gantt, que permitem ao planejador ter uma visão ampla do custo da obra de acordo com a execução (OLIVEIRA, 2015).

A etapa de planejamento a médio prazo se mostra de grande importancia, principalmente para os gestores da obra, uma vez que a partir desta análise é possível realizar uma programação de compras de materiais e equipamentos, necessidade de recursos, treinamentos e mão de obra extra, sem que haja interferencia negativa no andamento da obra (BERNARDES, 2001). Outro aspecto relevante é a possibilidade de estudar as restrições das atividades, ou seja, fatores que podem influenciar no não cumprimento das mesmas (LIMA, 2016). Entretanto, Bernardes (2001) aponta que apesar da programação a médio prazo possuir mais detalhes do que a longo prazo, ela não é suficiente para a condução diária de uma obra por ainda adotar uma abordagem generalista, apontando a necessidade da análise a curto prazo.

A função do planejamento a curto prazo é oferecer diretrizes claras e imediatas, extremamente ricas em detalhes que possibilitem a condução dos engenheiros de campo, mestre de obras e encarregados no decorrer da obra, em períodos semanais ou quinzenais (MAXIMIANO, 2000). Dessa forma, a programação a curto prazo é uma forma de monitoramento do cotidiano da obra. Lima (2016) cita que as atividades planejadas nesta etapa são as cumpridas nas previsões da programação a médio prazo que tenham a totalidade dos recursos disponibilizados em tempo hábil.

Além da hierarquização pelo prazo de cumprimento das atividades, com a ferramenta de mapeamento de processos há a possibilidade de organização de forma clara e resumida das etapas dos procedimentos, sua sequência e tempos (MATTOS, 2010). O mesmo autor ainda aponta a existencia de softwares que auxiliam o planejador. Entretanto estes programas não são capazes de substituir a capacidade intelectual de um profissional capacitado, e por isso é necessário ser criterioso com os dados de entrada nos programas para que seja possível usufruir de seus benefícios. 
Tão importante quando o planejamento das atividades é o controle de execução das mesmas. A curva $\mathrm{S}$ é uma ferramenta amplamente utilizada na gestão de obras para realizar uma comparação quantitativa do planejado versus o executado (ROCHA, 2010). Publio (2015) aponta a utilização deste instrumento, não apenas para comparação da execução das atividades, mas também dos custos empregados em determinados períodos e, também, da forma global acumulada.

Outra ferramenta de grande importância para o bom funcionamento de controle de uma obra é o cronograma físicofinanceiro, que não considera apenas a parte executável da atividade, mas também o elemento de custo. A ferramenta representa, segundo Nunes (2013), os aspectos físicos em conjunto com os financeiros em relação ao tempo e permite a apresentação do avanço real da obra. Assim, mensalmente ou semanalmente, as informações de prazo de entrega e contribuições financeiras em relação às etapas parciais são unidas e analisadas em conjunto, conforme cita Lima (2016). É possível a partir do cronograma a análise do custo total do mês e os custos acumulados. Em um planejamento ideal, o custo acumulado no final da obra se iguala ao orçamento da obra. Entretanto, em situações reais, atrasos e imprevistos podem deixar esses valores discordantes.

As atividades contidas no cronograma podem estar atreladas a diferentes graus de importancia uma vez que o atraso de uma operação pode interferir no desempenho da obra mais intensamente que outra atividade. A curva ABC é uma ferramenta gerencial que permite a separação dos insumos de um planejamento de maior ou menor importância/ impacto no custo de uma obra (ROCHA, 2010). A curva, que também pode ser representada em tabelas, classifica os insumos em custos decrescentes, ou seja, as primeiras linhas mostram os materiais, equipamentos ou serviços com valores maiores e, portanto, mais relevantes em um orçamento em termos de decisões de estocagem, negociação, cotações, etc (PAULA, 2015). Aliani (2015) aponta para a importancia do gestor da obra acompanhar a compra dos produtos do topo da curva $\mathrm{ABC}$, uma vez que eles são de grande importância para o custo final da obra.

Existem alguns itens para o planejamento de obras de restauro que demandam maior atenção como, por exemplo, a proteção de obras artísticas realizada por técnicos em restauro, testes e ensaios com materiais já não comuns no mercado, além da inclusão de arqueólogos e técnicos de restauro no corpo técnico da equipe (IPHAN, 2005). Dessa forma, segundo Campana (2003), os profissionais atuantes no planejamento e na execução do restauro devem ser especializados para que a integridade e originalidade da obra de arte sejam mantidas.

Mesmo que a equipe responsável pela execução da obra seja experiente, as obras de restauração requerem atenção diferencial uma vez que estas apresentem uma imprevisibilidade maior do que obras comuns, podendo resultar em alterações no cronograma e no resultado do empreendimento. Nem sempre as janelas de inspeções iniciais e documentos históricos fornecem dados completos para a compreensão exata das atividades a serem executadas. Por isso, esse tipo de obra necessita de um estudo prévio detalhado (BRAGA, 2003).

Diante dos conceitos citados, este trabalho tem por objetivo apontar as diferentes técnicas e como é possível aplicá-las nas obras de restauração, através de um estudo de caso. O presente estudo apresenta a obra de restauração da Igreja Santo Antônio de Glaura (Figura 1) em Ouro Preto - MG, iniciada no ano de 2019.

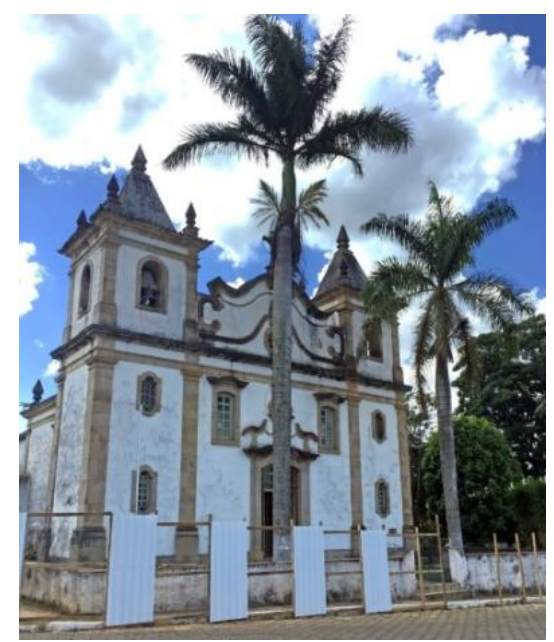

Figura 1: Matriz Santo Antônio de Glaura 
A matriz Santo Antônio de Glaura, que teve suas obras iniciadas em 1751 e possui tombamento federal da edificação e do acervo com data de 24 de outubro de 1962, processo n 465-T, inscrição 470, livro de Belas Artes, folha 86. O monumento é uma edificação em pedra, com fachada enquadrada em duas colunas e duas torres quadrangulares com janelas sineiras. Os altares e seus nichos são considerados pouco trabalhados, sendo a riqueza artística da igreja concentrada principalmente nos retábulos da nave (IEPHA/MG, 2002).

\section{METODOLOGIA}

\subsection{Metodologia adotada}

O presente estudo consistiu no acompanhamento da obra de restauro da Igreja Santo Antônio de Glaura, em Ouro Preto - MG, com a identificação e estudo das técnicas e ferramentas utilizadas no planejamento e controle do empreendimento examinado, além de entrevistas com profissionais da área. O estudo de caso realizou-se entre os meses de novembro de 2018 (data primeira visita técnica no local ainda na fase do orçamento) e finalizou-se em aabril de 2019 (data de fornecimento dos últimos dados do controle). Os dados apresentados neste trabalho foram disponibilizados com autorização da empresa responsável pela obra. A partir dos conceitos evidenciados, do estudo de caso e das entrevistas, foi feita uma discussão crítica das técnicas e dos desafios enfrentados no planejamento e controle de uma obra de restauração. A Figura 2 apresenta a metodologia adotada neste estudo.

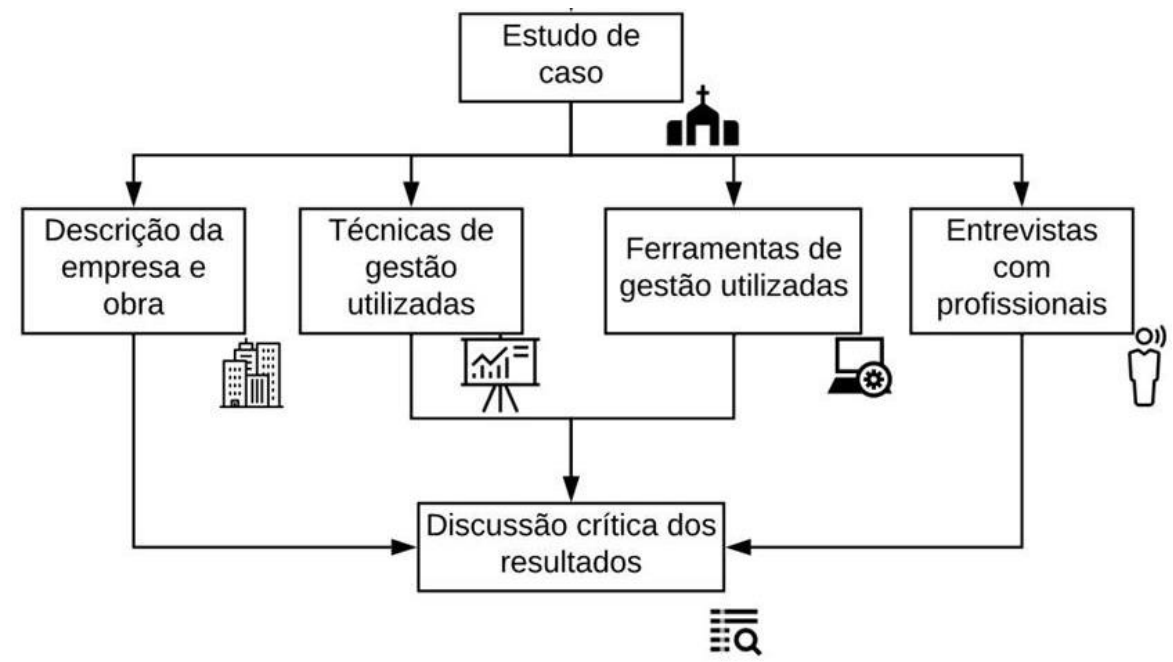

Figura 2: Esquematização da metodologia proposta

\subsection{Descrição da edificação}

A Igreja Matriz de Santo Antônio, obejto do estudo, se encontrava interditada pela defesa civil desde 2015 até janeiro de 2019, quando se iniciaram as restaurações. O escopo realizado pelo Instituto do Patrimônio Histórico e Artístico (IPHAN) contempla obras civis para consolidação estrutural e recuperação de cobertura, drenagem, instalação de sistema de proteção contra descarga atmosférica e atividades auxiliares com fornecimento e montagem de todos os equipamentos e materiais.

Um diagnóstico realizado pela empresa Acantos mostrou que todas as patologias estruturais encontradas no interior e exterior da edificação eram causadas pela falta de drenagem adequada. A restauração dos elementos artísticos, pintura e instalação de novo piso não fazem parte desse escopo, devido ao orçamento disponibilizado pela financiadora não ser sufuciente para tal. A Figura 3 mostra um corte transversal com marcação de trinca frontal interna dos projetos executivos. 


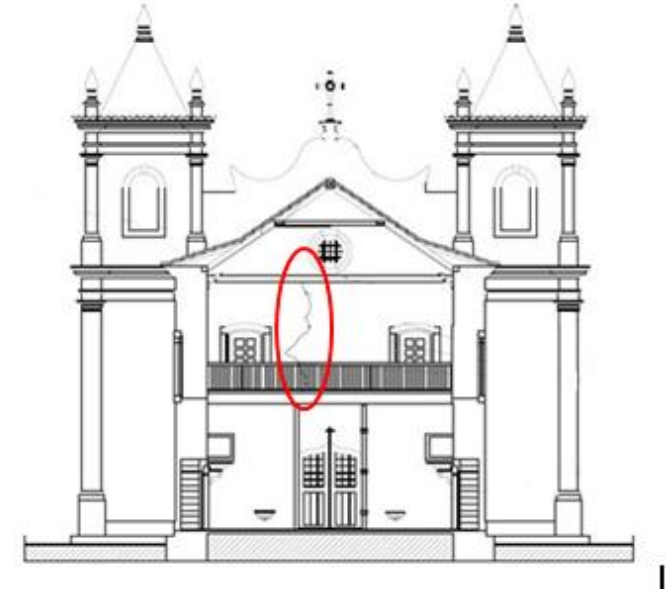

Figura 3: Corte transversal da igreja sinalizando patologia

Foram encontradas ainda outras trincas internas e externas à Igreja associadas a problemas estruturais e falhas na cobertura que ocasionavam acúmulo de água da chuva no interior da edificação.

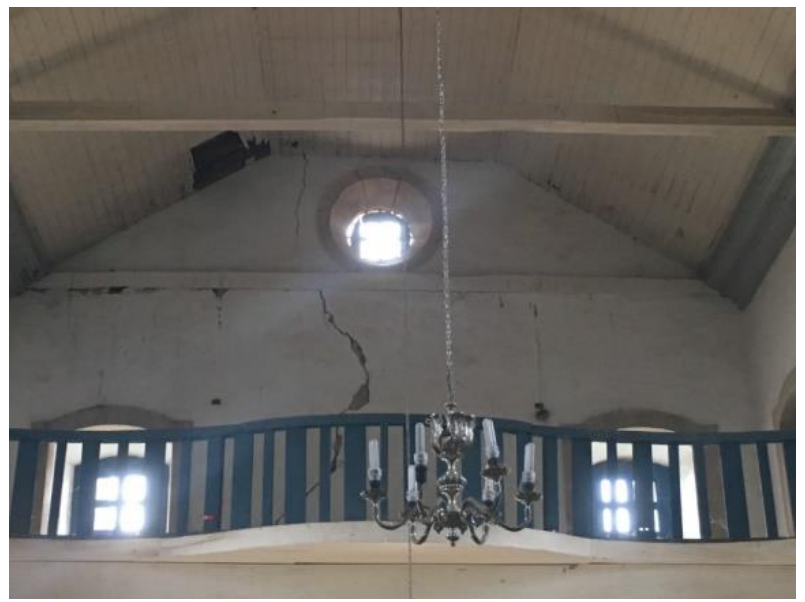

Figura 4:Trinca no interior do monumento

\section{RESULTADOS}

\subsection{Planejamento da obra}

A fase de planejamento da obra de resturação da Igreja Santo Antônio da Glaura foi iniciada após a avaliação dos documentos e cálculos preliminares de Composições dos Custos Unitários (CCUs), propostas técnicas e comerciais, realizadas na fase do orçamento pelo órgão fiscalizador, além dos projetos e contrato. As CCUs, além de servirem de base para o orçamento geral, auxiliaram nos controle dos custos. Foi possível perceber, nas fases posteriores de projeto, se o custo de um produto ou serviço já realizado estava dentro do estipulado. Caso o valor estivesse fora do planejado, seria realizada a análise de em quais outras CCUs esse valor poderia ser compensado. Após esta averiguação inicial, foram indicados alguns instrumentos de auxílio ao planejamento dos prazos a longo, médio e curto prazo. Ferramentas tais como cronogramas e histogramas puderam ser aplicados com base no orçamento e dados contratuais.

Para que o planejamento de longo prazo pudesse ser efetivado de maneira eficaz, foi elaborada uma planilha de compras revisada de acordo com cronograma e orçamento preliminares. Dessa forma, seria possível realizar o agendamento de compra de insumos e recursos de forma a auxiliar o planejamento a médio prazo de compras, programação de contratação de serviços terceirizados, etc. 
O planejamento a curto prazo foi realizado com base no planejamento a longo prazo através análise em conjunto com as programações a médio prazo. Assim, nas visitas diárias à obra, o engenheiro responsável realizava reuniões com o encarregado para alinhar as atividades da semana de forma coerente aos prazos estipulados, às condições climáticas e às adversidades que possam vir a ocorrer. Com o acompanhamento sistemático do progresso no canteiro, o cronograma da obra pôde ser avaliado toda vez que algum serviço sofresse atrasos ou adiantamentos. Sua reavaliação era realizada de forma rápida, podendo ser estudados alguns cenários diferentes de trocas lógicas de atividades, caso fossem necessárias, sem que a data de entrega fosse adiada.

\subsection{Ferramentas de acompanhamento e controle}

O acompanhamento das atividades no empreendimento acompanhado foi realizado principalmente através de ferramentas como planilhas de controle atualizadas diariamente pela equipe técnica da obra. Todas as atividades realizadas no canteiro de obra, assim como demais informações importantes, foram inseridas em relatórios diários, reunidos mensalmente e enviados com todas as outras ferramentas adotadas.

O cronograma concretizado na etapa de planejamento era atualizado constantemente com a alimentação de datas reais iniciais e finais das atividades. Com essas informações é possível gerar o gráfico de avanço físico ou curva $\mathrm{S}$ da obra que de forma rápida permite visualizar os avanços físicos em modo comparativo do planejado com o realizado. Nesta análise, os dados avaliados para comparação se baseiam no orçamento e faturamento inicial planejado e no controle de custos e faturamento reais em percurso da obra.

\begin{tabular}{|c|c|c|c|c|}
\hline VALE & & $\begin{array}{r}\text { PRO } \\
\text { RECUPERAÇÃC }\end{array}$ & $\begin{array}{l}\text { CURVA DE AVANÇO FÍSICO } \\
\text { O HEXÁGONO CONSULTORIA E ENGENHARIA } \\
\text { RUTURAL DA MATRIZ DE SANTO ANTÔNIO - GLAURA / OURO PRETO }\end{array}$ & $\square_{\text {HEXAGONO }}$ \\
\hline Contrato: & Término Previsto: 02/09/19 & Térwino Projetado: 29108n19 & Data de Status: 07/04/19 & \\
\hline
\end{tabular}

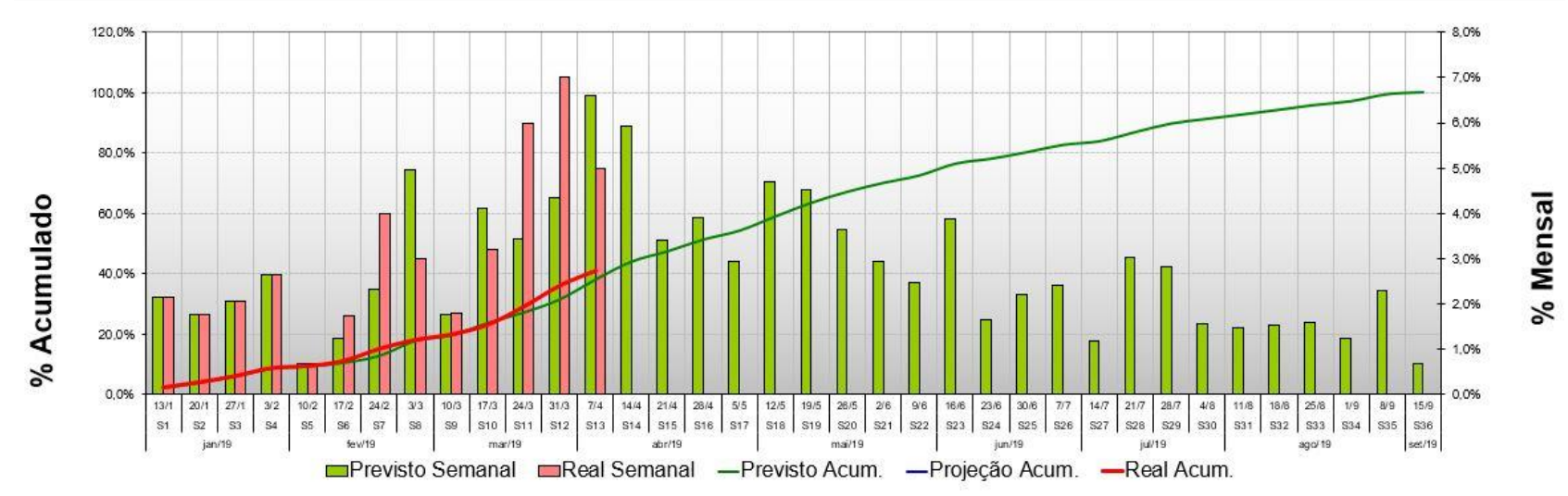

Figura 5: Curva S de avanço físico da obra de restauração da Igreja Santo Antônio de Glaura.

Com o acompanhamento sistemático do progresso no canteiro, o cronograma da obra pôde ser avaliado sempre que algum serviço sofresse atrasos ou adiantamentos. Sua reavaliação era realizada de forma rápida, podendo ser estudados alguns cenários diferentes de trocas lógicas de atividades, caso fossem necessárias, sem que a data de entrega fosse adiada ou causasse grandes danos ao cronograma de longo prazo proposto.

Foram também preparados os resumos de ordens de compras que serviam de base de dados para alimentação do controle de gastos. Este, por sua vez, realizado no software MS Excel, poderia ser filtrado e trazia diversas informações importantes, como a porcentagem de gastos em determinado fornecedor, a quantidade total de certo material comprado até o momento, saldo e dívidas com fornecedores, etc. Também compunham os custos da obra as despesas com mão de obra direta e indireta. Portanto, diariamente a presença dos funcionários foi contabilizada e repassada ao setor responsável da empresa.

Ainda foram montados histogramas de equipamentos (Figura 6) para o acompanhamento e controle da obra, e estes se mostraram de grande relevânica tanto para o gestor quanto para os fiscais. Através do histograma de equipamentos foi possível prever a logística de equipamentos e qual a melhor data para sua mobilização, abastecimento e desmobilização. Além disso, um segundo histograma de mão de obra direta e indireta pôde auxiliar no agendamento e contabilidade dos benefícios de trabalhadores em obra, como café, almoço e transporte. 


\begin{tabular}{|c|c|c|c|c|c|c|c|c|c|c|c|c|}
\hline \multicolumn{10}{|c|}{ HISTOGRAMA DE EQUIPAMENTOS } \\
\hline IT & DE SCRIÇÃo & DISTRIB. & Dezembro & Janeiro & Fevereiro & Março & Abril & Maio & Junho & Julho & Agosto \\
\hline 1 & Caminhonete com tração 4x4 & Prev. & 1 & 1 & 1 & 1 & 1 & 1 & 1 & 1 & 1 \\
\hline 2 & Micro-ônibus & Prev. & 1 & 1 & 1 & 1 & 1 & 1 & 1 & 1 & 1 \\
\hline 3 & Caminhão com carroceria de madeira & Prev. & 1 & 1 & 1 & 1 & 1 & 1 & 1 & 1 & 1 \\
\hline 4 & Mini escavadeira hidráulica & Prev. & & & & 1 & 1 & 1 & 1 & & \\
\hline 5 & Caminhão basculante & Prev. & & & & 1 & 1 & 1 & 1 & & \\
\hline 6 & Compactador de placa vibratória & Prev. & & & & & & & & 1 & 1 \\
\hline 7 & Guincho elétrico de coluna & Prev. & & & 1 & 1 & 1 & 1 & 1 & 1 & 1 \\
\hline 8 & Caçamba & Prev. & & & 1 & 1 & 1 & 1 & 1 & & \\
\hline 9 & Martelo rompedor elétrico & Prev. & & & & 1 & 1 & 1 & 1 & & \\
\hline
\end{tabular}

Figura 6: Histograma previsto de equipamentos

\subsection{Eficiência do planejamento e controle}

De um modo geral, a obra de restauração da Matriz de Santo Antônio de Glaura apresentou no decorrer dos meses analisados atividades de planejamento e controle eficientes. Essa percepção foi possível a partir das ferramentas utilizadas e da atualização periódica do cronograma que demonstraram que a execução da obra está além do planejado e os custos estão aquém do previsto.

Entretanto, a partir de análise crítica dos resultados, foi observada a existência de alguns elementos que influenciaram de forma negativa a execução da restauração. Alguns deles não estavam ao alcance da construtora por questões políticas e orçamentárias e outros não foram considerados apropriadamente no planejamento.

O primeiro ponto incoerente encontrado foi a escolha, por motivos políticos e orçamentários, da divisão da restauração da igreja em escopos diferentes. A obra em estudo compreende a execução de obras civis para consolidação estrutural e recuperação de cobertura, drenagem, instalação de sistema de proteção contra descarga atmosférica e atividades auxiliares. Entretanto, outras atividades também necessárias e relevantes de restauração artística e pintura não foram incorporadas neste projeto.

A finalização da obra em execução não assegura o inicio da próxima etapa, e nem mesmo qual empresa a realizará. Assim, pode ocorrer uma quebra cronológica que pode influenciar no desempenho da edificação ao longo do tempo, como, por exemplo, com o aparecimento de novas patologias ou o fim da vida útil de determinados sistemas. Além disso, a próxima etapa pode ser realizada por outra empresa que não presenciou a primeira etapa e não acumulou a expertise da obra em questão, tanto no corpo técnico quanto no tocante aos colaboradores de campo.

O segundo problema destacado, e muito comum nas obras de restauração, foi a incompatibilidade do planejado versus a real situação encontrada na edificação após o início da obra. No escopo do projeto se encontra a demolição do piso interno da igreja planejado em $5 \mathrm{~cm}$. Entretanto, após o início da obra foi descoberta a existencia de outras camadas de pisos precedentes que tornavam a sua demolição completa superior aos $5 \mathrm{~cm}$ planejados. Além disso, também foi verificado o desnivelamento de pisos entre alguns cômodos, fato desconhecido em projeto.

Para a instalação do dreno profundo no interior e exterior da igreja fori necessária a escavação, ao redor da edificação, que levou à descoberta de solos remexidos devido a diversos sepultamentos não registrados. De acordo com o engenheiro responsável, muitos lugares apresentam solos fofos ou até mesmo vazios. Esta falta de compactação encontrada no solo pode causar futuros problemas de recalques em fundações e outras patologias não previstas anteriormente. Sendo assim, será necessário um acompanhamento dos desníveis pelo IPHAN logo após o término desta primeira etapa.

Além disso, apesar do empenho no uso das ferramentas de gestão, foi observada a existencia de algumas falhas na elaboração do planejamento por parte da construtora. Como exemplo, o cronograma executivo não contou com a consideração dos índices pluviométricos da região e não foi realizado o cálculo da praticabilidade, que descreve a estimativa dos dias produtivos de cada mês, excluindo os dias de grandes chuvas. Além disso, somente algumas patologias foram descritas e detalhadas em projetos. A falta de um documento contemplando todos os danos apresentados pelo monumento antes da obra de restauração dificultou a correção das patologias e a gestão documental do monumento. 
Foram observadas também falhas de controle da obra. Embora houvesse um cômodo na casa de apoio com a finalidade de almoxarifado, não era realizado um controle de entrada e saída de materiais diversos como parafusos, pregos, ferramentas, mantas, lixas, etc. Dessa forma, não era realizado um controle de estoque que evitaria a compra de materiais desnecessários. Pode-se mencionar a sobra de materiais, tais como manta geotêxtil utilizada na execução dos drenos, como uma consequência dessa falta de gerenciamento.

Outra questão importante é que não foi realizada a gestão dos riscos da obra. As atividades que podem representar riscos de atrasos pra a obra não foram mapeados documentalmente. Sem o registro e o acompanhamento devido, diversas situações preveníveis ocorreram, tais como a demora da liberação do corte das palmeiras frontais pela prefeitura e burocracia para liberação da portaria do IPHAN autorizando estudos arqueológicos na obra, acarretando atrasos.

A arqueóloga Eliany Salaroli referiu, em entrevista, à importânica de um arqueólogo no acompanhamento de uma obra. Segundo Eliany, o profissional se faz necessário sempre em obras de restaurações em que escavações profundas façam parte do escopo do processo, como é o caso de uma restauração que inclua drenos profundos. Caso seja evidenciado algum vestígio arqueológico histórico ou pré-histórico, é necessário que se dê prosseguimento ao monitoramento arqueológico. Dessa forma, o profissional poderá resgatar este material com as técnicas adequadas e entregá-lo a uma instituição responsável, com a mínima interferência no cronograma da obra. A arqueóloga ressalta que, normalmente, as obras não param devido a descoberta de vestígios arqueológicos, pois somente em escavações com grandes volumes é preciso fazer um trabalho meticuloso que demanda tempo. Já em obras de restauração que abrangem escavações simples e rasas, o percurso das escavações pode ser adaptado ou até mesmo pode ser realizado o remanejamento das atividades enquanto os estudos arqueológicos são efetuados, não resultando em atrasos significativos nos cronogramas.

No trabalho realizado na Igreja Santo Antônio de Glaura, Eliany comenta que encontrou vestígios arqueológicos nas laterais do monumento (Figura 7). As escavações foram interrompidas até que fossem feitas as análises e cadastro do material encontrado, que foi devolvido para a paróquia realizar um novo enterramento. Para tanto, a obra não precisou ser paralisada, somente as escavações, havendo um remanejamento das atividades. Assim, o cronograma da obra teve que ser adaptado por alguns dias, mas não foi necessária nenhuma mudança que adiasse o avanço executivo.

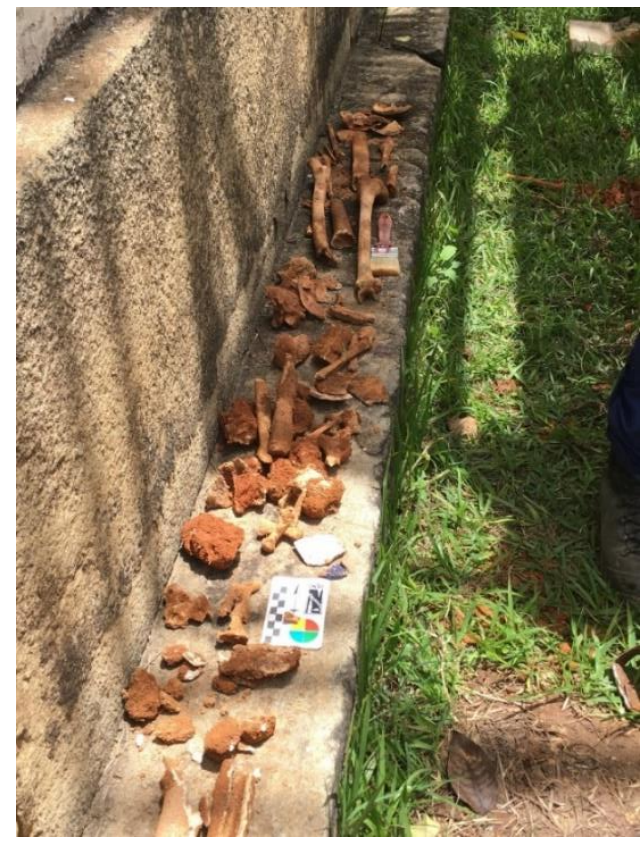

Figura 7: Ossadas encontradas após a abertura do dreno profundo na Igreja Santo Antônio de Glaura

Prever adversidades com antecedência aumenta o tempo de resposta do gestor, tanto no planejamento quanto no controle da execução. Dessa forma, é importante que, associado ao planejamento da obra, haja a colaboração de uma gestão de recursos humanos com competências técnicas comprovadas e especializadas. Em especial, cita-se a 
importância da qualificação de profissionais do ramo de restauração, como: técnico de restauração, arqueólogo, arquiteto e engenheiro especializados.

O controle de efetivo de execução da obra se mostrou eficaz, uma vez que o gestor realizava a análise diária de pequenas logísticas, como transporte e refeições, além de controlar atestados médicos e afastamentos dos colaboradores. Este controle, como parte do gerenciamento a curto prazo, também era importante para que os fiscais comprovassem a presença dos efetivos em obra.

Por fim, deve ser ressaltado que sem a experiência do engenheiro gestor, algumas decisões poderiam ter sido tomadas tardiamente, podendo ter ocasionado o descumprimento do cronograma ou até mesmo um retrabalho. As técnicas e ferramentas auxiliam bastante, mas elas por si só não controlam as atividades. É nesta etapa que a experiência do gestor faz a diferença para uma melhor interpretação dos dados coletados através das ferramentas e posterior tomada da decisão de como agir.

No planejamento e controle da obra de restauro da Igreja Santo Antônio de Glaura não foram aplicadas algumas ferramentas que poderiam auxiliar o gestor em decisões, tais como a gestão de riscos, mapeamento de processos e curva ABC. Através dessas ferramentas, possíveis problemas, como falta de material, erros de projetos não compatibilizados e má comunicação entre os encarregados e os operadores poderiam ser resolvidos com maior eficiência.

\section{CONCLUSÃO}

Inseridas em um setor tão competitivo como o da construção civil, as construtoras precisam investir em ações atreladas ao planejamento e ao controle de suas obras para conseguirem minorar os índices de desperdício e alcançar o lucro desejado com qualidade e segurança. Estas práticas devem ser adotadas e controladas de forma cotidiana especialmente em obras de restauração, nas quais há um alto grau de incerteza que implica diretamente no desafio da gestão.

Nesse sentido, este trabalho apresenta os aspectos adotados para o planejamento e controle da obra de restauração da Igreja Matriz Santo Antônio de Glaura. Nesse empreendimento foram utilizadas as seguintes técnicas de planejamento e controle: CCUs, cronograma físico, cronograma físico-financeiro, histogramas (mão de obra direta, mão de obra indireta e equipamentos), gestão de aquisições, curva $\mathrm{S}$ (física e financeira) e gestão de recursos humanos.

Diversos obstáculos foram encontrados ao longo da obra acompanhada, como o estado de conservação de materiais da estrutura e incidentes não previstos em projeto. Além destes, ocorreram também empecilhos políticos envolvendo burocracias na espera de liberação de e outorgas para a autorização do estudo arqueológico e do corte das palmeiras frontais.

Entretanto, mesmo com as adversidades enfrentadas, a execução da obra apresentou avanços além do planejado com custos menores que o esperado. Seguindo as previsões, a obra tende a ser entregue antes do prazo estipulado e com a margem de lucro acima do planejado. Para atender às previsões, as ferramentas já utilizadas no controle precisam ser mantidas e atualizadas cotidianamente, a fim de auxiliar o engenheiro na tomada de decisões futuras. Outras ferramentas também poderiam ser inseridas no planejamento e controle para melhor desempenho da obra, como a gestão de riscos, mapeamento de processos, curva $\mathrm{ABC}$ e compatibilização de projetos.

Em conclusão, as ferramentas aqui apresentadas auxiliam significativamente na tomada de decisões, entretanto é importante ressaltar que elas não fazem o papel mais importante: a avaliação criteriosa dos dados e o poder de geri-los. Portanto, cabe ao profissional capacitado se comprometer a registrar e interpretar com cautela e critério os resultados fornecidos pelas ferramentas, evitando impactos negativos na obra e contribuindo para o seu avanço físico e financeiro compatíveis com o planejado.

\section{AGRADECIMENTOS}

O presente trabalho foi realizado com apoio da Coordenação de Aperfeiçoamento de Pessoal de Nível Superior - Brasil (CAPES) - Código de Financiamento 001. Os autores também agradecem à FAPEMIG, CNPq e UFOP pelo apoio para a realização e apresentação dessa pesquisa. Somos gratos ainda pela infraestrutura e colaboração do Grupo de Pesquisa em Resíduos Sólidos - RECICLOS - CNPq. 


\section{REFERÊNCIAS}

ALIANI, C. Planejamento: Ferramenta indispensável para o canteiro de obras. Monografia UFMG, p. 35, 2015.

BERNARDES, M. M. S. Desenvolvimento deum modelo de planejamento controle da produção para micro e pequenas empresas de construção. Porto Alegre: Universidade do Rio Grande do Sul, 2001.

BOMFIM, C. A. A. Gestão de projetos em conservação e restauro. Belo Horizonte. 2017.

BRAGA, M. Conservação e Restauro: Arquitetura. Rio de Janeiro : [s.n.], 2003.

CAMPANA, J. S. Gestão em obras de restauro: uma metodologia de apropriação de custos em obras de restauração. Universidade Federal do Rio de Janeiro, Rio de Janeiro, Abril 2003.

GOLDMAN, P. Introdução ao Planejamento e Controle de Custos. São Paulo: Pini, 2004.

IEPHA/MG. Igreja Matriz de Santo Antônio em Glaura (Ouro Preto, MG). IPHAN, 2002. Disponivel em: <http://portal.iphan.gov.br/ans.net/tema_consulta.asp?Linha=tc_belas.gif\&Cod=1383>. Acesso em: 02/06/2019 Junho 2019.

IPHAN. Manual de Elaboração de Projetos Programa Monumenta. Caderno Técnico , Brasília, v. 1, 2005.

LAFETÁ, P. L. Planejamento e Controle de Obras: Soluções Contratuais para viabilização da introdução do planejamento em canteiros com a atuação de empreiteiras. Centro Universitário de Brasília. Brasília. 2013.

LIMA, E. A. M. Estudo da Contribuição das Metodologias do Lean Construction e do Gerenciamento de Projetos do PMI para o Planejamento e Controle da Produção de Obras. Universidade Federal do Rio de Janeiro, Rio de Janeiro, 2016.

MATTOS, A. D. Planejamento e Controle de Obras. [S.1.]: PINI, 2010.

MAXIMIANO, A. C. A. Introdução à Administração. 5a . ed. São Paulo: Atlas S.A., 2000.

NUNES, J. A. S. Gerenciamento de obras civis. Belo Horizonte: UNIVERSIDADEFEDERAL DE MINAS GERAIS, 2013.

OliveIRA, F. G. Planejamento Operacional: Estudo de Caso do Setor de Compras de uma Distribuidora de Medicamentos. Limeira: Universidade Estadual de Campinas, 2015.

PAULA, J. G. A. Orçamento de Obras. Belo Horizonte: Universidade Federal de Minas Gerais, 2015.

PUBLIO, H. L. Planejamento físico/financeiro de obras civis. Belo Horizonte: Universidade Federal de Minas Gerais, 2015.

ROCHA, L. F. F. A importância do orçamento na construção civil.. Belo Horizonte: Universidade Federal de Minas Gerais, 2010. 